\title{
To Assess the Clinical Outcome of the Total Hip Arthroplasty-A Study in Tertiary Care Hospital, Bangladesh
}

\author{
A. K. M. Latiful Bari ${ }^{1 *}$, Md. Rashed Hasan ${ }^{2}$, Md. Wares Ali ${ }^{3}$, Md. Anisur Rahman ${ }^{4}$, A. K. Al Miraj ${ }^{5}$, Shohel Mahmud \\ $\mathrm{Khan}^{6}$, Md. Kawsur Ahmed ${ }^{7}$, Md. Akter Hossain ${ }^{8}$ \\ ${ }^{1}$ Medical Officer, Department of Orthopedic Surgery, Bangabandhu Sheikh Mujib Medical University (BSMMU) Dhaka, Bangladesh \\ ${ }^{2}$ Junior Consultant, Orthopaedic Surgery, Kushtia Medical College Hospital, Kushtia Bangladesh \\ ${ }^{3}$ Junior Consultant, Orthopedic \& Trauma Surgery Department, Mugda Medical College Hospital, Dhaka, Bangladesh \\ ${ }^{4}$ Lecturer, Forensic Medicine, Kushtia Medical College, Kushtia Bangladesh \\ ${ }^{5}$ Research Assistant, Department of Vascular Surgery, BSMMU, Dhaka, Bangladesh \\ ${ }^{6}$ Junior Consultant, Department of Orthopaedic Surgery, Bangabandhu Sheikh Mujib Medical University (BSMMU), Dhaka, Bangladesh \\ ${ }^{7}$ Assistant professor (Orthopedic surgery), City Medical College, Dhaka, Bangladesh \\ ${ }^{8}$ Junior consultant, Orthopedic \&Trauma Surgery Department, Mymensingh Medical College Hospital, Mymensingh, Bangladesh
}

Article History

Received: 23.02 .2021

Accepted: 02.04 .2021

Published: 12.04.2021

Journal homepage: https://www.easpublisher.com

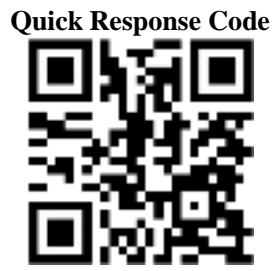

Abstract: Introduction: Total hip Arthroplasty may be a surgery, which relives pain associated with hip joint. The success of Total Hip Arthroplasty is its ability to alleviate the pain related to hip pathology, while maintaining the mobility and stability of the hip. Objective: This study was undertaken to assess the Clinical outcome of the entire hip Arthroplasty in our institution. Material \& Methods: This retrospective and prospective study was administered on 500 patients of Total Hip Replacement operated within the Department of Orthopedic Surgery, Bangabandhu Sheikh Mujib Medical University (BSMMU) Dhaka, Bangladesh between the study periods of August 2016 to August 2019. All patients underwent a typical clinical and laboratory evaluation that has briefly information about age, sex, address, clinical history and routine investigation which were done pre operatively. X-Ray of hip with AP view was done. Pre-op Range of Motion, deformities and its values were recorded for the study by clinical evaluation and Modified Harris hip scoring was done preoperatively and postoperatively with follow up at 4 weeks, 6 months, 1 year and at yearly intervals. Results: This study was conducted on patients with age ranging from 25 to 65 years with a mean age of $37.50 \pm 14.15$ years at the time of surgery. The main indication for surgery was AVN in 360 patients (72\%). The mean total pre-operative harris hip score score was 49.74. The maximum score being, 73 and the minimum, being 37 . Post operatively the total mean score was 85.12 , with the 65 being the minimum and 96 being the maximum. The most common complication was stress shielding (24\%). Acetabular component loosening was seen in $2 \%$ cases and femoral stem loosening was found in $12 \%$ cases. Calcar resorption was present in $8 \%$ cases. Conclusion: In conclusion, Total hip Arthroplasty with or without cement gives good clinical and functional outcomes and is decided by multiple factors, like indication for total hip Arthroplasty, placement of prosthesis, and therefore the operative technique. The results of the procedure must be evaluated in long-term studies. Our study suggests that the entire Hip Replacement can provide satisfactory clinical outcomes after short term duration of follow-up.

Keywords: Total Hip Replacement, Harris Hip Score, Clinical Outcome.

Copyright (C) 2021 The Author(s): This is an open-access article distributed under the terms of the Creative Commons Attribution 4.0 International License (CC BY-NC 4.0) which permits unrestricted use, distribution, and reproduction in any medium for non-commercial use provided the original author and source are credited.

\section{INTRODUCTION}

Total hip Arthroplasty may be a surgery, which has relieved many people from incapacitating pain arising from the hip joint [1]. The primary total hip replacement is assumed to possess been wiped out London by Phillip Wiles in 1938 [2]. The procedure was further developed within the 1950 s by McKee and Farrar [3], which was later developed by Sir John Charnley who within the late 1960s [4, 5]. Total hip replacement (THR) relieves the pain and functional disability experienced by patients with moderate to severe arthritis of the hip, improving their quality of life. Preliminary data suggest that uncemented total hip Arthroplasty have a comparatively low revision rate and excellent prosthetic durability for as long as 15 years. Compared with cemented hip Arthroplasty, however, patients have a better incidence of low-grade temporary thigh pain. Although short-term results appear to be less satisfactory compared with cemented hip Arthroplasty, after 5 to twenty years, the leads to the 2 procedures are similar. It's a highly cost-effective procedure. 
Evaluation of outcome is vital to work out the sturdiness of the procedures like total hip replacement (THR). The Harris hip score is that the most generally used rating system for evaluating hip Arthroplasty. This study is undertaken to assess the Clinical outcome of the entire hip Arthroplasty.

\section{Material \& Methods}

This retrospective and prospective study was carried out on 500 patients of Total Hip Replacement operated in the Department of Orthopaedic Department of Orthopedic Surgery, Bangabandhu Sheikh Mujib Medical University (BSMMU) Dhaka, Bangladesh between the study periods of August 2016 to August 2019. Information on the patients was compiled from clinical database, case files and operation theatre records for retrospective cases and Questionnaire and case files were used for prospective cases. Patients were followed up for regular intervals at 4 weeks, 6 months and 1 year. All the patients above 25 years of age who had undergone Total Hip Arthroplasty for isolated hip pathologies at our hospital were included. The patients who had undergone Total Hip Replacement with deformities or pathologies of other joints of the lower limb, which may have had an adverse bearing on the functional outcome of the surgery, were excluded. 80 patients were available for the follow-up with their previous operative records, annual X-ray films and follow-up papers. 420 fresh cases had undergone unilateral total hip replacement. Detailed history and proper clinical examination was done. The deformity and Range of movements were measured with goniometer.

All the patients were assessed using Modified Harris Hip Score pre operatively and postoperatively. Radiograph of the pelvis with both hips with proximal half of shaft of femur AP view was taken for all patients. The radiograph was evaluated for size of the acetabulum bone stock of the acetabulum, any protrusion and periacetabular osteophyte formation, the structural integrity of the acetabulum, need for bone grafting, size of the femoral canal and radiological limb length discrepancy. Templating was done for the acetabular and femoral components. All the patients were operated using standard postero lateral approach. Prophylactic antibiotics, unless contraindicated, were used in all patients 24 hours preoperatively and upto 72 hours postoperatively and continued in the form of oral antibiotics for 7 days. DVT prophylaxis was given in the form of low molecular weight heparin for first five days after surgery. Drains were removed 24 to 48 hours after surgery. First post op day, check X-rays are taken. The patient is taught static quadriceps exercises; knee and ankle mobilization exercised and made to sit. Second post op day dressing changed and smaller dressing is applied. Gait training was started using a walker with weight bearing to tolerance. At around 10th-12th post op day sutures are removed and discharged from the hospital. Harris hip scoring was done postoperatively at the time of discharge, 4 weeks, 6 months and 1 year follow-up.

\section{Data Analysis}

The following methods of statistical analysis have been used in this study. The Excel and SPSS software packages Version 21.0 were used for data entry and analysis. The results were averaged (mean + standard deviation) for each parameter for continuous data and numbers and percentage for categorical data presented in Table and Figure. Proportions were compared using Chi-square test of significance and Paired t' test. In the entire above test the " $p$ " value of less than 0.01 was accepted as indicating statistical significance.

\section{ObServations \& Results}

The study was carried out on 500 hips of 500 patients who underwent uncemented Total Hip Replacement. This study was conducted on patients with age ranging from 25 to 65 years with a mean age of $37.50 \pm 14.15$ years at the time of surgery, $400(80 \%)$ Were males and $100(20 \%)$ were females. All the patients underwent unilateral total hip replacement. 120 total hip replacements were done on the left side and 380 on the right side. The main indication for surgery was avascular necrosis in 360 patients $(72 \%)$.

Table-1: Showing underlying pathology indicative of Total Hip Arthroplasty in the study

\begin{tabular}{|c|l|c|c|}
\hline & Diagnosis & Frequency & Percentage (\%) \\
\hline $\begin{array}{c}\text { Avascular } \\
\text { Necrosis } \\
\text { (AVN) }\end{array}$ & Idiopathic AVN & 110 & 22 \\
\cline { 2 - 4 } & Post Traumatic AVN & 20 & 4 \\
\cline { 2 - 4 } & Steroid Induced & 70 & 14 \\
\cline { 2 - 4 } & Avn due to Chronic Alcoholism & 160 & 32 \\
\hline Osteoarthritis & 50 & 10 \\
\hline Ankylosing Spondylitis & 20 & 4 \\
\hline \multicolumn{2}{|l|}{ Rheumatoid Arthritis } & 20 & 4 \\
\hline Sickle Cell Disease & 50 & 10 \\
\hline Total & 500 & 100 \\
\hline
\end{tabular}

74\% patients underwent uncemented Total Hip Arthroplasty whereas $26 \%$ patients underwent
Cemented Total Hip Arthroplasty. We used Modified Harris Hip Score to evaluate the functional outcome. 
For the total score and each of the parameters, higher score implies lesser disability. The mean total preoperative score was 49.74. The maximum score being, 73 and the minimum, being 37 . Post operatively the total mean score was 85.12 with the 65 being the minimum and 96 being the maximum. With regards to the different parameters in the scoring system i.e., pain, gait, functional activity, absence of deformity and ROM, there was a statistically significant improvement ( $\mathrm{P}$ value of $<0.001)$ in the post-operative score when compared to pre-operative score.

Table-2: Paired student $t$ test between Pre-operative and post-operative scores according to the various parameters of the Modified Harris Score System

\begin{tabular}{|c|c|c|c|c|c|c|c|c|}
\hline $\begin{array}{l}\text { Parameters of } \\
\text { modified HHS }\end{array}$ & & 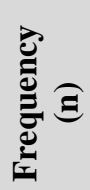 & 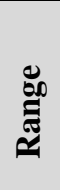 & 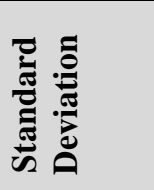 & $\stackrel{\Xi}{\Sigma}$ & $\sum^{\frac{x}{\pi}}$ & $\stackrel{\Xi}{\stackrel{\Xi}{\sharp}}$ & 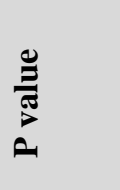 \\
\hline \multirow[t]{2}{*}{ Pain } & Preoperative & 50 & 20 & \pm 5.226 & 10 & 30 & 18.20 & 0.00 \\
\hline & Postoperative & 50 & 14 & \pm 4.120 & 30 & 44 & 38.08 & \\
\hline \multirow[t]{2}{*}{ Function (gait) } & Preoperative & 50 & 28 & \pm 9.710 & 2 & 30 & 20.72 & 0.00 \\
\hline & Postoperative & 50 & 14 & \pm 3.220 & 19 & 33 & 29.96 & \\
\hline \multirow{2}{*}{$\begin{array}{l}\text { Function } \\
\text { (activity) }\end{array}$} & Preoperative & 50 & 10 & \pm 2.433 & 0 & 10 & 4.14 & 0.00 \\
\hline & Postoperative & 50 & 2 & \pm 0.942 & 8 & 10 & 9.36 & \\
\hline \multirow{2}{*}{$\begin{array}{l}\text { Absence of } \\
\text { deformity }\end{array}$} & Preoperative & 50 & 2 & \pm 0.598 & 2 & 4 & 3.36 & 0.00 \\
\hline & Postoperative & 50 & 0 & \pm 0.000 & 4 & 4 & 4.00 & \\
\hline \multirow[t]{2}{*}{ ROM score } & Preoperative & 50 & 2 & \pm 0.605 & 2 & 4 & 2.96 & 0.00 \\
\hline & Postoperative & 50 & 1 & \pm 0.404 & 4 & 5 & 4.80 & \\
\hline \multirow[t]{2}{*}{ Total Score } & Preoperative & 50 & 56 & \pm 17.195 & 17 & 73 & 49.74 & 0.00 \\
\hline & Postoperative & 50 & 31 & \pm 8.594 & 65 & 96 & 85.66 & \\
\hline
\end{tabular}

On Comparison of the pre-operative versus post-operative scores according to the Functional outcome scores. 90-100 had excellent results, 80-90 had good, 70-79 fair, 60-69 poor and below 60 for a failed result. Pre-operatively $94 \%$ had a poor score. The results showed a significant improvement, wherein $36 \%$ had an excellent score and $42 \%$ showed good and $20 \%$ fair results. $2 \%$ patient had a poor score.

Table-3: Comparison of the pre-operative versus post-operative scores according to the Functional outcome scores

\begin{tabular}{|l|c|c|}
\hline Outcome & Pre-operative & Post-operative \\
\hline Score Grade & & \\
\hline Poor & $470(94 \%)$ & $10(2 \%)$ \\
\hline Fair & $30(6 \%)$ & $100(20 \%)$ \\
\hline Good & $0(0 \%)$ & $210(42 \%)$ \\
\hline Excellent & $0(0 \%)$ & $180(36 \%)$ \\
\hline Total & $50(100 \%)$ & $500(100 \%)$ \\
\hline
\end{tabular}

Table-4: The mean total pre-operative Harris Hip score

\begin{tabular}{|l|c|c|}
\hline \multirow{2}{*}{ Studies } & Pre-operative & Post-operative \\
\cline { 2 - 3 } & Harris hip score & Harris His Score \\
\hline Our study & 49.74 & 85.66 \\
\hline Wixson et al. $[11]$ & 44 & 93 \\
\hline Siwach et al. [9] & 44 & 83.5 \\
\hline Ganeshan et al. $[13]$ & 44 & 88 \\
\hline Chandrasekhar et al. [10] & 45.04 & 88.44 \\
\hline Russoti et al. [14] & 47 & 97 \\
\hline
\end{tabular}

The mean total pre-operative Harris Hip score was 49.74 , which improved post operatively to a mean score of 85.66. There was statistically significant improvement in postoperative Harris hip score. TABLE 4 shows comparison of mean pre-operative and postoperative Harris hip scores of various studies. We compared functional outcome scores with the Outcome according to underlying cause and found that $100 \%$ patients with osteoarthritis as the diagnosis had an excellent outcome. All the patients of Rheumatoid Arthritis and $80 \%$ patients of sickle cell disease had fair outcome. $50 \%$ patient of Ankylosing spondylitis had poor outcome. So upon cross tabulation between outcome score and cause of disease was statistically 
significant. (P value 0.00) Statistical analysis reveals that outcome of the THA can be significantly dependent on underlying cause of disease. On Radiological Evaluation, in this study we had a normal acetabular inclination (30-50 degree) in all the Patients. Femoral stem was placed in varus in $8 \%$ of total cases and centrally in $88 \%$ cases. Valgus placed femoral stem was present in $4 \%$ cases. In our study $81.81 \%$ of neutrally placed femoral stem had excellent and good outcome scores and significant relation was found between placement of femoral stem and functional outcome scores. Early complications noted were fairly less in our study Shortening was seen in $6 \%$ cases, infection was found in $4 \%$ cases which was superficial, Periprosthetic fracture and hip dislocation was found in 1 case each. The most common late complication was stress shielding $(24 \%)$ acetabular component loosening was seen in $2 \%$ cases and femoral stem loosening was found in $12 \%$ cases. Calcar resorption was present in $8 \%$ cases. Femoral loosening was present in $75 \%$ of cases where femoral stem was placed in varus. However, no loosening was observed in $79.5 \%$ cases where there was centrally placed femoral stem.

\section{Pre-Operative and Post-Operative Radiographs}

These are some of the Pre-operative, postoperative and follow up radiographs of some of the cases in our study.

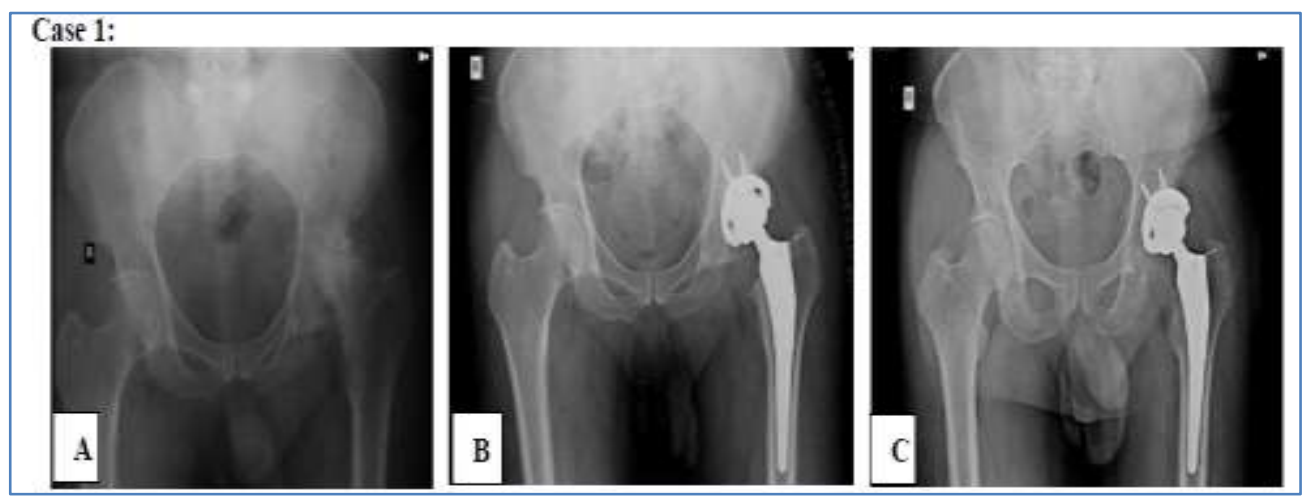

Fig-1: A. X-ray Pre- operative Radiograph; B. X-ray Post-operative Radiograph; C. X ray year follow up radiograph

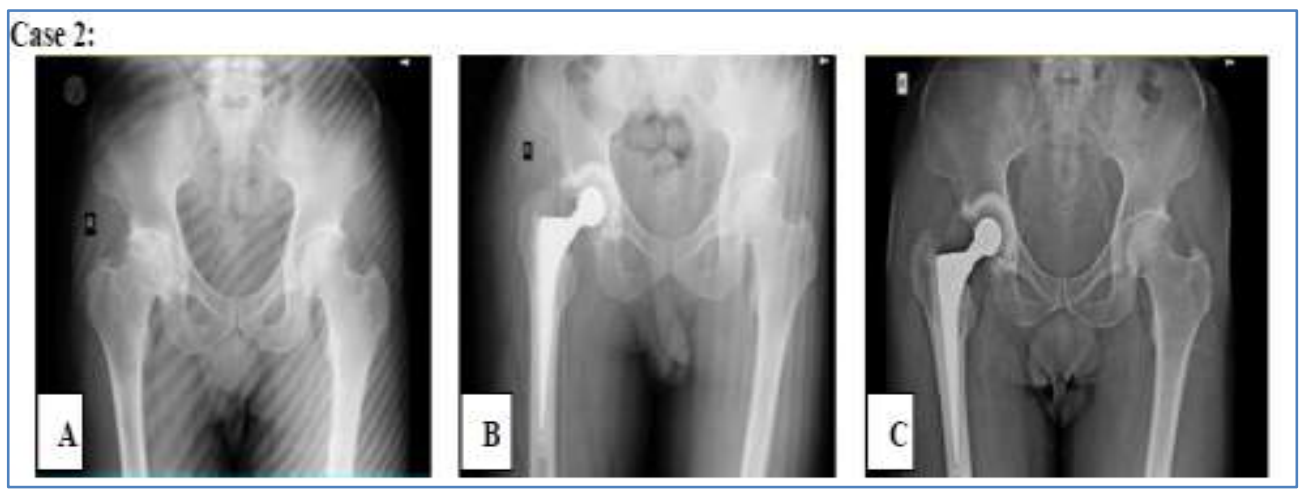

Fig-2: A. X-ray Pre- Operative Radiograph; B. X-ray Post-operative Radiograph

\section{DISCUSSION}

Total hip Arthroplasty is a well-documented surgical procedure. It relieves pain and functional disability experienced by patients with moderate to severe arthritis of the hip, improving their quality of life. In our study, $20 \%$ of the patients were found to be in the 50 years and above age group, with age ranging from 20 to 75 years and an average age of $40.50 \pm 12.15$ years. The mean age of our study was comparable with study of Unger AS et al. [6], where the mean age was 39.9 years with range of 14-72 years. However, in our study there were no statistical significant between age and functional outcome of the patients. Singling out the primary indication of the procedure is difficult, but reports of Eftekhar [7], Harkess [8], document the arthritis group to be the most common indication. In our study Avascular necrosis was the most common indication for replacement in which AVN due to chronic alcoholism constitute $32 \%$ cases followed by idiopathic AVN (22\%) and steroid induced AVN (14\%) and post traumatic AVN (4\%). We used Harris hip score to assess the functional outcome in our study which is the most widely used scoring system for evaluating hip Arthroplasty. Excellent and good pain relief and function were obtained in $78 \%$ of patients which is comparable to study of RC Siwach et al. [9], in which excellent or good outcome was achieved in $75 \%$ patients and Chandrasekhar et al. [10], where $84 \%$ had excellent results. The mean total pre-operative Harris Hip score was 49.74 , which improved post operatively to a mean score of 85.66 . There was statistically significant improvement in postoperative Harris hip score. Table 4 shows comparison of mean pre-operative 
and post-operative Harris hip scores of various studies. In our study mean Pre op Harris Hip score and mean post-operative Harris hip score in cemented THR was 44.85 and 83.69 which was comparable with Wixson et al. [11], which is 42 and 90 and Sandesh Reddy Yaratapalli et al. [12], which is 36 and 88. The mean Pre op Harris Hip score and mean post-operative Harris hip score in uncemented THR was 86.35 and 51.46 which were like Wixson et al. [11]. However, there was no statistical significance found between the sort of Arthroplasty and functional outcome scores. Another factor which will be of important in determining the result of Arthroplasty the Indication of total hip Arthroplasty. In our study all the patients of osteoarthritis had excellent outcome, all the patients of atrophic arthritis and $80 \%$ patients of red blood cell disease had fair outcome. $50 \%$ patients of MarieStrumpell disease had poor outcome scores. These results are comparable the study of Ganeshan et al. [13], as they concluded that function outcome of total hip Arthroplasty is more in osteoarthritis as compared to atrophic arthritis. In our study we found that there was statistical significance between the indication of surgery and final outcome. There was no incidence of migration of acetabular component in our study however acetabular loosening within the form Osteolysis in zone 2 was present in $2 \%$ of cases after 1 year follow up and it had been within the case of MarieStrumpell disease. In study of Sandesh Reddy Yeratapalli [12], acetabular component loosening was seen in 1 case $(2.6 \%)$ and Russoti GM et al. [14], found acetabular component loosening in 1 case and femoral stem loosening in 3 cases. Acetabular component loosening and femoral stem loosening had statistically significant correlation with the underlying pathology indicative of total hip Arthroplasty. As acetabular stem loosening was seen in 50\% cases off Marie-Strumpell disease and femoral stem loosening was present in half the cases of Marie-Strumpell disease and $60 \%$ cases of red blood cell disease. Stress shielding was present in $24 \%$ of total cases during this study which was comparable study of Engh C et al. [15], who had found stress shielding in $12 \%$ cases. Stress shielding was present altogether the cases of Marie-Strumpell disease , atrophic arthritis and red blood cell disease and its association was found to be statistically significant. Calcar resorption was seen in $8 \%$ cases of our study after 1 year follow up whereas in Soballe K et al. [16], found calcar resorption in $21 \%$ of total cases and in Calcar resorption was seen altogether the cases of Marie-Strumpell disease , 50\% cases of atrophic arthritis and $20 \%$ cases of red blood cell disease. However, the association between the underlying cause and calcar resorption was found to be significant. Other radiological complications like pedestal formation, cortical thickening and fibrous lucent layer weren't encountered in our study. In our study quite $1-1.5 \mathrm{~cm}$ shortening was present in $12 \%$ of cases which was managed with footwear correction within the sort of shoe raise which is like findings of Ganeshan et al. [13], showing 1-1.5 $\mathrm{cm}$ shortening in $13 \%$ cases other complication in our study were infection (4\%), dislocation (2\%), periprosthetic fracture $(2 \%)$ and heterotrophic ossification (2\%). This was comparable study of Anne Lubbeke et al. [17], who reported $0.7 \%$ prosthetic joint infection, $3.2 \%$ dislocation and $3.4 \%$ periprosthetic fracture. Post-operative infection was present in $4 \%$ of the cases which was superficial. These cases were managed successfully with long duration of adequate antibiotic cover and delayed suture removal. This was comparable study of Babak Siavashi et al. [18], who had reported infection in 3 cases. In our study $2 \%$ of cases had an evidence of dislocation which was managed with open reduction within the immediate post op period. This was comparable study of Sandeshreddy Yaratpalli et al. [12], who reported $2.6 \%$ dislocation. $2 \%$ cases reported periprosthetic fracture one month after the surgery. It had been a Vancouver Type C fracture managed with open reduction and internal fixation. In our study, heterotrophic ossification was found in $2 \%$ cases whereas in study of Sandeshreddy Yaratpalli et al. [12], heterotrophic ossification was reported in $13 \%$ cases.

\section{Conclusion}

In conclusion, Total hip Arthroplasty with or without cement gives good clinical and functional outcomes and is decided by multiple factors, like indication for total hip Arthroplasty, placement of prosthesis, and therefore the operative technique. The results of the procedure must be evaluated in long-term studies. Our study suggests that the entire Hip Replacement can provide satisfactory clinical and radiographic outcomes after short term duration of follow-up. However, subsequent long-term studies must be administered so as to clarify the progression of Osteolysis which will influence the clinical result and implant longevity. Though the study wasn't freed from complications, the general functional and clinical outcome showed good results.

\section{REFERENCES}

1. Harkess, J.W. (1998). "Arthroplasty of the hipll. Campbell's Operative Orthopaedics Mosby.

2. Petty, W. P. (1991). WB Saunders, Total Joint Replacement-VI, Lower Extremity Replacement. The Hip. Philadelphia, 189-465.

3. McKee, G.K., W.F.J. (1966). Replacement of arthritic hips by the McKee-Farrar prosthesis. $J$ Bone Joint Surg [Br], 48: 245-259.

4. J, C., Total hip replacement. (1974). JAMA. 230:1025-1028.

5. Charnley, J. (2012). Low friction arthroplasty of the hip: theory and practice. Springer Science \& Business Media.

6. Unger, A. S., Inglis, A. E., Ranawat, C. S., \& Johanson, N. A. (1987). Total hip arthroplasty in 
rheumatoid arthritis: a long-term follow-up study. The Journal of arthroplasty, 2(3), 191-197.

7. Eftekhar, N. S. (1983). Total hip replacement using principles of low-friction arthroplasty: The Hip. Surgery of the Musculoskeletal System. Churchill Livingston, 3, 13-23.

8. Harkess, J.W. (1982). Arthroplasty of hip, Campbells Operative Orthpeadics, Edited by AH Crenshaw, 8th edition, Vol. 1: CV Mosby Company, St. Louis, Washington DC, Torto.

9. Siwach, R. C., Kadyan, V. S., Sangwan, S. S., \& Gupta, R. (2007). A retrospective study of total hip arthroplasty. Indian journal of orthopaedics, 41(1), 62.

10. Gupta, S., Singh, P. K., Saoji, K., Deshpande, S., \& Khan, S. (2017). To study the clinical outcome of total hip Arthroplasty. Indian Journal of Orthopaedics, 3(4), 350-355.

11. Wixson, R. L., Stulberg, S. D., \& Mehlhoff, M. (1991). Total hip replacement with cemented, uncemented, and hybrid prostheses. A comparison of clinical and radiographic results at two to four years. The Journal of bone and joint surgery. American volume, 73(2), 257-270.

12. Harshavardhan, G., \& Vijayaraghavan, P. V. (2014). Functional and radiological outcomes of total hip replacement in non-traumatic indications. Int. J. Curr. Microbiol. App. Sci, 3(3), 153-158.
13. Ram, G. G., Thamodaran, B., Ashok, T. R., Perumal, S., \& Varthi, V. P. (2013). Analysis of functional and radiological outcome of total hip replacements in rheumatoid and osteoarthritis patients. Open Journal of Rheumatology and Autoimmune Diseases, 2013.

14. Russotti, G. M., Coventry, M. B., \& Stauffer, R. N. (1988). Cemented total hip arthroplasty with contemporary techniques. A five-year minimum follow-up study. Clinical orthopaedics and related research, (235), 141-147.

15. Engh, C. A., Bobyn, J. D., \& Glassman, A. H. (1987). Porous-coated hip replacement. The factors governing bone ingrowth, stress shielding, and clinical results. The Journal of bone and joint surgery. British volume, 69(1), 45-55.

16. Søballe, K., \& Christensen, F. (1988). Calcar resorption after total hip arthroplasty. The Journal of arthroplasty, 3(2), 103-107.

17. Lübbeke, A., Katz, J. N., Perneger, T. V., \& Hoffmeyer, P. (2007). Primary and revision hip arthroplasty: 5-year outcomes and influence of age and comorbidity. The Journal of rheumatology, 34(2), 394-400.

18. Siavashi, B., Mohseni, N., Zehtab, M. J., \& Ramim, T. (2014). Clinical outcomes of total hip arthroplasty in patients with ankylosed hip. Archives of Bone and Joint Surgery, 2(1), 25.

Citation: A. K. M. Latiful Bari et al (2021). To Assess the Clinical Outcome of the Total Hip Arthroplasty-A Study in Tertiary Care Hospital, Bangladesh. EAS J Orthop Physiother, 3(2): 16-21. 